\title{
Conservative management of a transdiaphragmatic fistula
}

\author{
I Gee, G M Wood
}

\begin{abstract}
Case reports of transdiaphragmatic fistulas connecting subphrenic collections and empyemas are uncommon. We report the rare complication of a fistulous connection between a subphrenic collection and the bronchial tree.

(Thorax 2000;55:438-439)
\end{abstract}

Keywords: transdiaphragmatic fistula; subphrenic abscess

\section{Case report}

An 82 year old man was admitted following an episode of coffee ground vomiting. $\mathrm{He}$ had experienced a dull ache in the epigastrium for one week and had a history of a duodenal ulcer 20 years previously. He looked pale with a regular pulse of $100 \mathrm{bpm}$ and there was mild epigastric tenderness. His haemoglobin was $123 \mathrm{~g} / 1$.

Gastroscopic examination showed a dilated stomach with fluid residue and the pylorus was narrowed to a pinhole; the duodenum could not be seen. He was started on lansoprazole and over the following week his condition stabilised. His haemoglobin fell to $107 \mathrm{~g} / 1$ but he did not pass melaena.

He then became unwell with a pyrexia of $38^{\circ} \mathrm{C}$, was tachypnoeic, and developed coarse crackles in the right lower chest. A diagnosis of right basal pneumonia was made and he was treated with intravenous cefuroxime and clarithromycin. Blood cultures were taken which subsequently grew a coagulase negative Staphylococcus, thought to be a skin contaminant. His temperature settled and his chest radiograph showed only patchy shadowing at the right base. An abdominal ultrasound scan, requested because of an increase in the serum level of alkaline phosphatase, was normal. His condition improved over the next four weeks and his chest signs and symptoms resolved. $\mathrm{He}$ had no further vomiting and was discharged home.

Six weeks later he was re-admitted with a haemoglobin of $59 \mathrm{~g} / \mathrm{l}$. He was transfused with six units of blood and discharged home three days later with a haemoglobin of $134 \mathrm{~g} / 1$. A barium enema examination was ordered to investigate further the cause of his recurrent anaemia.

Two weeks later he was re-admitted with a one week history of a cough productive of purulent sputum. On examination he was apyrexial, had peripheral oedema, and the right base was dull to percussion and associated with decreased breath sounds. Abdominal examination was normal.

His haemoglobin was $125 \mathrm{~g} / \mathrm{l}$, white cell count $6.3 \times 10^{9} / 1$, and chest radiography showed cardiac failure with upper lobe venous diversion and bilateral pleural effusions, with a homogenous opacity at the right base which was thought not to be entirely caused by the effusion.

He was started on co-amoxiclav and erythromycin but attempted intercostal aspiration of the pleural fluid was unsuccessful. A barium enema was performed and indicated early diverticular disease in the sigmoid colon and a tiny outpouching at the hepatic flexure with some possible tethering. The significance of this was uncertain but possible causes included the previous perforation of a colonic diverticulum.

Bronchoscopic examination of the right bronchial tree indicated some inflammatory changes in the right lower lobe. A foul faeculent smell was noted and the possibility of a transdiaphragmatic fistula was raised. An abdominal ultrasound examination demonstrated a $12 \mathrm{~cm}$ collection of fluid lateral to the liver, suggestive of a subphrenic abscess. Later that day a pigtail drainage catheter was inserted into the subphrenic collection and thick pus was drained.

Two days later a tubogram was performed to assess the size of the abscess cavity. A small subphrenic cavity was demonstrated before the patient started to cough up contrast medium. Radiography showed a fistula between the subphrenic cavity and the bronchial tree (fig 1).

Pus from the subphrenic abscess cavity yielded heavy growths of methicillin resistant Staphylococcus aureus and Enterococcus spp. Both sputum and bronchial washings yielded methicillin resistant $S$ aureus. The patient was treated with teicoplanin and the cavity drained externally. Subsequent tubograms over the following week showed that the fistula had closed and the abscess cavity became smaller.

Following drainage of the abscess the patient made a good recovery and his chest symptoms resolved. He was discharged home and was well when seen two months later.

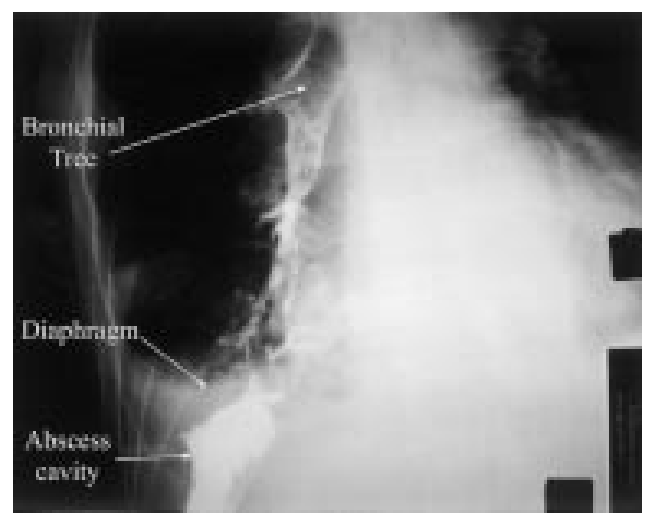

Figure 1.A transdiaphragmatic fistula linking the subphrenic collection to the bronchial tree.
12 April 1999 26 April 1999
George Eliot Hospital Street, Nuneaton, I Gee Dr G M Wood email:

Received 4 September 1998 Returned to authors 23 December 1998 


\section{Discussion}

Case reports of transdiaphragmatic fistulas connecting subphrenic collections and empyemas are uncommon. ${ }^{1-3}$ This elderly patient presented with chest symptoms and was found to have a subphrenic abscess by ultrasound scanning. These pathologies were not initially thought to be connected but opinion changed when the patient expectorated contrast medium which had been injected into the subphrenic abscess cavity.

It was decided that the best treatment option was to continue percutaneous drainage of the abscess and to administer antibiotics. This led to a satisfactory outcome and the transdiaphragmatic fistula closed spontaneously when the abscess cavity had drained for a few days.

It is not clear why this patient developed a subphrenic abscess but it must have arisen following his first hospital admission because the original ultrasound examination was normal. The possibilities include perforation of a colonic diverticulum or a duodenal ulcer. The barium enema findings suggested that a small diverticular perforation had occurred which had sealed spontaneously and the microbiology suggested a faecal origin to the abscess, so this seems the most likely explanation. Alternatively, the dyspeptic symptoms, the fall in haemoglobin, and the previous history of a peptic ulcer raises the possibility of a silent perforation of a duodenal ulcer with subsequent healing. Pyloric stenosis prevented this possibility being confirmed at gastroscopy. The erosion of an empyema through the diaphragm following an earlier chest infection seems unlikely.

1 Zeebregts CJ, van der Heyden AH, Ligtvoet EE, et al. Transphrenic dissemination of actinomycosis. Thorax 1996;51:449-50.

2 Chen AC, Liu CC, Yao WJ, et al. Actinobacillus actinomycte comitans pneumonia with chest wall and subphrenic abscess. Scand F Infect Dis 1995;27:289-90.

3 Okano A, Shibata M, Sato A. A case of empyema with subphrenic abscess (Japanese). Kansenshogaku Zasshi 1992;66: 643-7.

\section{LETTERS TO THE EDITOR}

\section{Mechanism of osteoporosis in patients with cystic fibrosis}

In a recent issue of Thorax Haworth and coworkers reported that low bone mineral density - that is, osteoporosis-commonly occurred in patients with cystic fibrosis. These results supported previous reports of osteopenia in patients with cystic fibrosis. ${ }^{2-4}$ However, the mechanism of bone loss in these patients has not been elucidated.

Although the pathogenesis of osteoporosis is probably multifactorial in patients with cystic fibrosis, the increased production of cytokines-primarily tumour necrosis factor $\alpha(\mathrm{TNF}-\alpha)$ - may play a critical role in adult patients. ${ }^{3}$ Among the important factors implicated in the pathogenesis of bone loss are circulating cytokines such as TNF- $\alpha$, interleukin (IL) -1 , and IL-6. TNF- $\alpha$ is a potent inhibitor of bone collagen synthesis and stimulator of osteoclastic bone resorption, the net effect of which is to cause bone loss. Experimental animal studies have also shown that the neutralising antibody to TNF- $\alpha$ slowed the bone elongation rate and bone marrow hyperplasia, and decreased trabecular bone volume. ${ }^{6}$ It has been reported that the production of $\mathrm{TNF}-\alpha$ by lung macrophages is increased in patients with cystic fibrosis. $^{78}$ The increased production of $\mathrm{TNF}-\alpha$ is also implicated in the pathogenesis of weight loss and cachexia in various diseases. Because body weight is associated with bone mineral content in normal subjects and those with cystic fibrosis, the weight loss or cachexia associated with increased production of TNF- $\alpha$ may also be involved in the pathogenesis of bone mineral deficit in these patients. Taken together, the increased production of cytokines, particularly $\mathrm{TNF}-\alpha$, may be a contributing risk factor for bone loss in patients with cystic fibrosis. It is therefore reasonable to assume that anti-inflammatory treatment with proinflammatory cytokines may prevent the development of osteoporosis.

The putative mechanism of bone loss is partly explained by the recent study in which treatment with an oral corticosteroid reduced both pamidronate induced bone pain and the level of TNF- $\alpha$ in patients with cystic fibrosis. ${ }^{4}$ The measurement of serum levels of cytokines including TNF- $\alpha$ may therefore provide a means of identifying cystic fibrosis patients who are at risk of rapid bone loss.

SHINJI TERAMOTO

Department of Internal Medicine, San-no Hospital,

International University of Health and Welfare, 3-35-14-305 Ikebuku-to, Toshima-ku,

Tokyo, fapan 171-0014 email:shinjit-tky@umin.ac.jp

1 Haworth CS, Selby PL, Webb AK, et al. Low bone mineral density in adults with cystic fibrosis. Thorax 1999;54:961-7.

2 Howorth CS, Selby PL, Webb AK, et al. Severe bone pain after intravenous pamidronate in adult patients with cystic fibrosis. Lancet 1998 ; 352:1753-4.

3 Teramoto S, Matsuse T, Ouchi Y. Increased cytokines may be responsible for the pamidronate-induced bone pain in adult patients

. Lancet 1999;352:1753-4.

4 Howorth CS, Selby PL, Webb AK, et al. Oral corticosteroids and bone pain after pamidronate in adults with cystic fibrosis. Lancet 1999 , 353:1886.

5 Manilagas SC. Roles of cytokines in bone resorption. Bone 1995;17 (2 Suppl):63-7s.

6 Vukicevic S, Marusic A, Stavljenic A, et al. The roles of tumor necrosis factor-alpha in the generation of acute phase response and bone loss in rats and talc granulomatosis. Lab Invest 1994;70:386-91.

7 Eonfield TL, Panuska JR, Konstan NM, et al. Inflammatory cytokines in cystic fibrosis lungs. Am 7 Respir Crit Care Med 1995;152:2111-6.

8 Pfeffer KD, Huecksteadt TP, Hoidal JR. Expression and regulation of tumor necrosis factor in Respir Cell Mol Biol 1993;9:511-9.

AUTHORS' REPLY We thank Shinji Teramoto for his continued interest in our work and note his current (and previous) comments about the possible role of proinflammatory cytokines in the development of low bone mineral density in patients with cystic fibrosis. ${ }^{1}$ As stated in our discussion, tumour necrosis factor $\alpha$, interleukin 1, and interleukin 6 may influence osteoclast activity in patients with cystic fibrosis. ${ }^{2}$ In fact, the significant negative relationship between the mean bone mineral density $\mathrm{Z}$ score and the $\mathrm{C}$ reactive protein concentration in our study provides the first evidence of an association between chronic pulmonary infection/inflammation and low bone mineral density in the cystic fibrosis population. ${ }^{2}$

Cystic fibrosis patients with low bone mineral density do not necessarily have osteoporosis. It is important to emphasise that the precise histomorphometric characteristics of cystic fibrosis bone have not been comprehensively described. In our study $38 \%$ of patients were vitamin $\mathrm{D}$ insufficient, which may predispose them to osteoporosis, but $7 \%$ of patients had 25-hydroxyvitamin D levels associated with osteomalacia. ${ }^{2}$ Thus, some patients could have both osteoporosis and osteomalacia. Furthermore, a recent report suggested that the bone disease of cystic fibrosis was complex and possibly unique. ${ }^{3}$

We have previously reported that bone pain is common in patients with cystic fibrosis after intravenous pamidronate and that it might be prevented by the concomitant use of oral corticosteroids. ${ }^{4}$ It is important to clarify that this was a retrospective observation and has not been evaluated prospectively.

CHARLES HAWORTH KEVIN WEBB Manchester Adult Cystic Fibrosis Unit, South Manchester University Hospitals NHS Trust, Wythenshawe Hospital, Manchester M23 9LT, UK

1 Teramoto S, Matsuse T, Ouchi Y. Increased production of TNF- $\alpha$ may play a role in osteoporosis in cystic fibrosis. Chest 1997;112:574.

2 Haworth CS, Selby PL, Webb AK, et al. Low bone mineral density in adults with cystic fibrosis. Thorax 1999;54:961-7.

3 Haworth CS, Freemont AJ, Webb AK, et al. Hip fracture and bone histomorphometry in a young adult with cystic fibrosis. Eur Respir $\mathcal{F}$ 1999;14:478-9.

4 Haworth CS, Selby PL, Webb AK, et al. Severe bone pain after intravenous pamidronate in adult patients with cystic fibrosis. Lancet 1998; 352:1753-4.

5 Haworth CS, Selby PL, Webb AK, et al. Oral corticosteroids and bone pain after pamidronate in adults with cystic fibrosis. Lancet 1999; 353:1886. 


\section{Spirometry in primary care}

Contrary to Dr Pearson's assertion in his reply in the May 1999 issue of Thorax, spirometry and forced expiratory volume in one second $\left(\mathrm{FEV}_{1}\right)$ are not yet here to stay in general practice. ${ }^{1}$ The evidence is just not good enough

We were concerned by the inaccuracies in his letter which simply serve to underline our unease with the chronic obstructive pulmonary disease (COPD) guidelines. We will come to these later but, firstly, how is FEV related to peak expiratory flow rate (PEFR) in patients with COPD? Is $\mathrm{FEV}_{1}$ really essential in the day to day management of COPD?

Spirometry is central to the accurate diagnosis of COPD in many patients. The ratio of $\mathrm{FEV}_{1}$ to $\mathrm{FVC}$ is indispensable in differentiating restrictive from obstructive patterns of respiratory breathlessness. But does $\mathrm{FEV}_{1}$ on its own offer additional information about COPD which is not available with PEFR? FEV, represents the volume of air expired during the first second of forced expiration whereas PEFR represents the maximal flow rate (usually attained in the first 100 milliseconds). Both are derived from the flow rate, but the nub of the argument is what happens after peak flow is reached. Pearson suggests that one needs to go, not to epidemiology, but to physiology to understand this issue. $\mathrm{He}$ suggests that, in patients with COPD, flow rate falls dramatically after peak expiratory flow is reached which is certainly the case in the diagram (albeit mislabelled) which he presents. However, his flow-volume trace differs considerably from the flow-volume curves produced by many other researchers and it is precisely the lack of sound epidemiological evidence to support his argument which makes his conclusions seem unsafe. $^{23}$ Patients with obstructive airway disease demonstrate some degree of airway collapse during forced expiration which is partly explained by the loss of elastic support of alveoli and respiratory bronchioles. In fact, the pattern of the flow-volume curve can be almost identical for asthma and COPD and this supports the close correlation observed between FEV and PEFR. ${ }^{4}$ When the absolute values of $\mathrm{FEV}_{1}$ and PEFR are compared, the correlation is high $(r=0.78-0.95) .{ }^{5}$ Little work has been done on the correlation between PEFR and $\mathrm{FEV}_{1}$ for $\mathrm{FEV}_{1}$ values of less than one litre. It is conceivable that the strength of correlation will be reduced at low levels of $\mathrm{FEV}_{1}$ or PEFR. But what is the significance of this possibility? Symptoms and signs rather than $\mathrm{FEV}_{1}$ guide the management of COPD in the majority of cases. We have little treatment to offer at present to patients with advanced COPD.

While spirometry offers a significant advantage to primary care physicians and nurses in the diagnosis of COPD, it is unlikely to have a role in the day to day management of this disease. The provision of spirometry in primary care would have significant financial and organisational implications which cannot be justified on current evidence. On this basis, open access to lung function laboratories seems preferable to a primary care based service. Spirometry in primary care risks inaccuracy from unsound operator techniques due to infrequent use and potential failure to calibrate an electronic spirometer regularly.

Finally, a brief word about Dr Pearson's reply to our letter. We were disappointed that he accused us of misquoting from Kelly and
Gibson. ${ }^{6}$ Dr Pearson is simply wrong in stating that there were 10 subjects with COPD. Kelly and Gibson mentioned eight patients (with a positive steroid trial and therefore presumably not COPD), and in these the correlation coefficient between individual $\mathrm{FEV}_{1}$ and PEFR values remained between 0.68 and 0.98 . We were also surprised that he criticised the quotation of the paper by Richie from the Lancet on the basis of the date of publication. ${ }^{7}$ This has surely nothing to do with the validity of the data. Furthermore, Lebowitz's observation that the FEV ${ }_{1}$ and PEFR show close correlation in healthy individuals emphasises the reliability and reproducibility of PEFR.

There is no evidence that $\mathrm{FEV}_{1}$ is more reproducible on a single occasion than PEFR. The papers by Malo et al and Verschelden et al relate to home recordings and hardly seem relevant to this issue. We refer Dr Pearson to another paper by Malo in which he showed that $\mathrm{FEV}_{1}$ is similar to PEFR in terms of nonvalid recordings. ${ }^{9}$ Finally, FEV , has not been shown to be superior to PEFR as a prognostic tool and, in fact, the evidence suggests that PEFR may be useful in this respect. ${ }^{101}$

The basis for using spirometry rather than peak flow in the day to day management of COPD demands a more rigorous approach than is evident from either the COPD guidelines or Dr Pearson's reply to our letter. The issue is far from resolved and current evidence is an inadequate basis on which to recommend the widespread practice of spirometric testing in primary care.

PATRICK T WHITE DERMOT NOLAN Department of General Practice and Primary Care,

Guy's, King's and St Thomas'Medical School, Weston Education Centre, London SE5 9PF, UK

1 Nolan D, White P. FEV ${ }_{1}$ and peak expiratory flow in COPD management. Thorax 1999;54:468.

2 Williams EM, Madgwick RG, Morris MJ. Tidal expired airflow patterns in adults with airway obstruction. Eur Respir f 1998;12:1118-23.

3 Jayamanne DS, Epstein H, Goldring RM. Flow volume curve contour in COPD: correlation with pulmonary mechanics. Chest 1980;77: $749-59$.

4 Bass $\mathrm{H}$. The flow volume loop: normal standards and abnormalities in chronic obstructive pulmonary disease. Chest 1973;63:171-6.

5 Paggiaro PL, Moscato G, Giannini D. Relationship between peak expiratory flow and FEV 1 . ship between peak expiratory
Eur Respir f 1997;10:39-41S.

6 Gibson GJ, Kelly CA. Relationship between FEV and peak expiratory flow in patients with chronic airflow obstruction. Thorax 1998;43:335-6.

7 Ritchie BA. A comparison of forced expiratory volume and peak flow in clinical practice. Lancet 1962;ii:271-3.

8 Lebowitz MD, Knudson RJ, Robertson MS Significance of intraindividual changes in maximal flow volume and peak expiratory flow measurements. Chest 1982;81:566-70.

9 Leroyer C, Perfetti L, Trudeau C, et al. Comparison of serial monitoring of peak expiratory flow and FEV, in the diagnosis of occupational asthma. Am 7 Respir Crit Care Med 1998;158:827-32.

10 Simons LA, McCallum J, Simons J, et al. Relationship of peak expiratory flow rate with mortality and ischaemic heart disease in elderly Australians. Med f Aust 1997;166:526-9.

11 Tilvis R, Valvanne J, Sairanen S, et al. Peak expiratory flow is a prognostic indicator in elderly people. $B M \mathcal{F} 1997 ; 314: 605-6$.

AUTHOR'S REPLY Drs White and Nolan agree that spirometry is essential for the diagnosis of COPD and, on this basis alone, I would stand by the recommendation of the guidelines that GPs need to have access to spirometry. The COPD guidelines ${ }^{1}$ set out three options: GP owned spirometers, a mobile service visiting practices intermittently, or open access services at hospital. Whichever option is preferred locally, the spirometric tests must be performed by trained staff to ensure adequate quality control. Single measures of peak expiratory flow $(\mathrm{PEF})$ are not adequate. It is colleagues in primary care who have encouraged those involved in guidelines to believe that most GPs would prefer to have access to a spirometer in their practice. The BTS COPD consortium has been promoting spirometry for the diagnosis of COPD since, without a correct diagnosis, the chance of accurate treatment is low. ${ }^{2}$ How the service is provided is a matter of local choice, not for national dictat.

With regard to the day to day management of COPD after the diagnosis has been objectively made, Drs White and Nolan are concerned that spirometry may be unnecessary. In fact, no-one is recommending frequent regular spirometric testing. Serial measurements of $\mathrm{FEV}_{1}$ can and do provide evidence of progression over the years, but cannot detect changes over periods of less than a few years with any degree of confidence because the rate of decline is small relative to the coefficient of variability for the measurement. Since PEF is even more variable, it is of even less value as a short term outcome measure, except in those with an asthmatic element where large changes may be apparent within days. The assessments of bronchodilator drug outcome in clinical COPD practice are therefore based on subjective responses. Research studies employ more objective health status measures.

I do not wish to get into an argument about the relative merits of PEF and FEV, which could fill many pages. We will continue to disagree on many of their points. I will confine myself to two issues.

Anyone who measures PEF and spirometry on a regular basis will recognise that $\mathrm{PEF}$ is a much more limited and more variable measure. ${ }^{3}$ The issue has probably been considered too obvious to justify formal studies. It is important to be careful, when looking at such comparator data as do exist, to ensure the correct method of statistical analysis has been performed. Bland and Altman set out the reasoning clearly, ${ }^{4}$ and their arguments are particularly relevant to the use of correlation coefficients to relate PEF and $\mathrm{FEV}_{1}$. For two measures that are dependent on the same predictors (age, sex and height), there will always be a linear regression correlation present as long as patients of different age, sex, and height are included.

Secondly, the use of PEF in asthma is of greatest value when recorded as serial measurements several times per day. The repeated measures compensate for the high variability of individual readings and provide data on symptomatic episodes outwith the clinic and on large changes of airway size that are typical of asthma. Serial PEF is less helpful in COPD with its reduced natural variability of airway dimensions. The second paper by Malo compared home spirometry with home PEF and noted poor compliance for both. The comparison that would be relevant is with supervised spirometry recorded by trained staff, which is why the guidelines emphasise the need for staff training.

Finally, I am heartened by data presented at the recent British Thoracic Society meeting in which spirometry was used in primary care as a screening tool in a research project. ${ }^{5}$ It offered spirometry to all adults over 45 attending the surgery (smokers and nonsmokers) and detected $6 \%$ of those studied as having undiagnosed but symptomatic COPD, a high yield of treatable disease from 
an inexpensive programme. Other primary care studies are in progress. I remain of the view that, in time, all GPs will have easy access to spirometry and be able to interpret the results as efficiently as they presently measure and manage blood pressure or blood sugar.

$M$ G PEARSON Aintree Chest Centre, Fazakerley Hospital, Liverpool $L 97 A L$,

1 British Thoracic Society. Guidelines on the management of chronic obstructive pulmonar disease. Thorax 1997;52(Suppl 5):S1-24.

2 Rudolf $M$, on behalf of the COPD Consortium. Making spirometry happen. Thorax 1999;54 A43.

3 Quanjer PH. Standardised lung function testing. Official Statement of the European Respiratory Society. Eur Respir $\mathcal{F}$ 1993;6(Suppl 16):5-40.

4 Bland JM, Altman DG Statistical methods for assessing agreement between two methods of clinical mo

5 Halpin DMG, Williams S, Timon S, et al. Home or surgery screening for COPD Thorax 1999; or surgery screen
54(Suppl 3):A43.

\section{Asthma guidelines}

One problem with large studies that focus on a limited number of patient relevant outcomes endorsed by Tattersfield and Harrison ${ }^{1}$ is that the mean response to a given drug may hide a wide variability in individua response. This is particularly likely to occur in patients with symptomatic asthma despite treatment with low/moderate doses of inhaled corticosteroids. Studies have shown marked heterogeneity of airway inflammation and disordered airway function in these patients ${ }^{2-4}$ and there are wide differences in the effects of the candidate drugs on these measures. Smaller crossover studies comparing the effects of different treatments in patients who have been extensively characterised are needed to establish whether important heterogeneity of response occurs. Such studies may uncover easily identifiable patien characteristics that predict a response to an individual drug.

$$
\begin{array}{r}
\text { R H GREEN } \\
\text { I D PAVORD } \\
\text { Department of Respiratory Medicine } \\
\text { E Thoracic Surgery, } \\
\text { Glenfield Hospital, } \\
\text { Groby Road, } \\
\text { Leicester LE3 } 9 Q P \text {, }
\end{array}
$$

1 Tattersfield AE, Harrison TW. Step 3 of the asthma guidelines. Thorax 1999;54:753-4. 2 Turner MO, Hussack P, Sears MR, et al. nophilia. Thorax 1995;50:1057-61.

3 Crimi E, Spanevello A, Neri M, et al. Dissociation between airway inflammation and airway hyperresponsiveness in allergic asthma. Am $\mathscr{f}$ Respir Crit Care Med 1998;157:4-9. Green RH, Pavord ID, Woltmann G, et al. Eosinophilic airway inflammation, symptoms and airway responsiveness in adults with asthma.
(Abstract submitted to Am 7 Respir Crit Care Med 1999)

5 Pavord ID, Brightling CE, Woltmann G, et al. Non-eosinophilic, corticosteroid unresponsive asthma. Lancet 1999;353:2213-4.

AUTHORS' REPLY Patients with asthma clearly vary in their response to drugs and it is possible that smaller detailed studies will allow the identification of patients more likely to respond to a particular drug. For such a test to be useful in practice, however, it would need to be easily accessible, reliable, and have a very high predictive value. History suggests that it is often more practicable for the patient to undergo a trial of a drug, rather than to undergo an indirect assessment which is unlikely to be $100 \%$ predictive of the response and hence may result in some patients not receiving a drug from which they would benefit.

A E TATTERSFIELD T HARRISON Division of Respiratory Medicine, University of Nottingham, City Hospital Nottingham NG5 1PB, $U K$

\section{Respiratory questionnaires in COPD}

The use of health status as an outcome measure in chronic obstructive pulmonary disease (COPD) is becoming more popular. We therefore welcome the publication of information which improves the choice of appropriate questionnaire. The recent paper by Rutten-van Mölken and colleagues could have made an important contribution to this area. ${ }^{1}$ However, we are seriously concerned about the validity of their comparison between the St George's Questionnaire (SGRQ) and the Chronic Respiratory Questionnaire (CRQ).

The clinical usefulness of the CRQ is limited because it is interviewer led while the SGRQ is self-administered. The development of a validated self-administered version of the CRQ would be a major advantage for clinical trials and clinical practice. The authors give the impression that a validated self-administered version of the CRQ already exists and have used this in their study. However, such a version is not described in the original reference as claimed and has never been disseminated by publication. ${ }^{2}$

We have recently been working with the original authors of the CRQ to develop and validate a self-reported CRQ and the results have so far only been published in abstract form. ${ }^{34}$ We therefore believe that the results described in the paper are devalued by the misleading implication that a self-report version of the CRQ has been correctly developed.

J WILLIAMS
S J SINGH
M D L MORGAN
Department of Respiratory Medicine,
Glenfield General Hospital,
Leicester LE3 $9 Q P$,

1 Rutten-van Mölken M, Roos B, Van Noord JA An empirical comparison of the St George's Respiratory Questionnaire (SGRQ) and the Chronic Respiratory Disease Questionnaire (CRQ) in a clinical setting. Thorax 1999;54:995-1003.

2 Guyatt GH, Berman LB, Townsend M, et al. A measure of quality of life for clinical trials in chronic lung disease. Thorax 1987;42:773-8.

3 Williams J, Singh S, Morgan MDL. A comparison between a self-reported Chronic Respiratory Questionnaire (CRQ-SR) and the conventional interviewer led CRQ. Eur Respir f 1999; 14(Suppl 30): $118 \mathrm{~s}$

4 Williams J, Singh S, Guyatt GH, et al. The reproducibility of a self reported Chronic Respiratory Questionnaire (CRQ-SR). Eur Respir F 1999;14(Suppl 30):263s.

AUTHOR'S REPLY Validation of a quality of life questionnaire needs to be an ongoing process because the measurement properties of a questionnaire may vary depending on the population and the context in which it is used. Our paper, in which we compare the self-reported CRQ and SGRQ, is a contribution to the validation of the self-reported version of the CRQ. Williams and colleagues have made a head to head comparison of the self-reported and interviewer led versions of the CRQ, which is also an important contribution to the validation process.

We did not develop the Dutch self-reported version of the CRQ. We have used the Dutch self-reported version of the CRQ, which has been on the market for several years and is mainly used in studies initiated by the industry. To avoid confusion and enhance the comparability of the results we decided it was better to use this existing version than to develop yet another version of the same instrument.

The response of Williams and colleagues may give the impression that there are big differences between the self-reported and interviewer led Dutch versions of the CRQ. This impression is wrong. The phrasing of the questions in the self-reported version is exactly the same as in the interviewer led version. The dyspnoea domain is still "individualised". The response options are also exactly the same. The only difference is that they are printed behind the questions instead of on separate cards.

I would suggest that the information of the various validation studies should be brought together so that the developers of the original CRQ can decide on one standard version of the self-reported questionnaire.

$$
\begin{array}{r}
\text { M P M H RUTTEN-VAN MÖLKEN } \\
\text { Institute for Medical Technology Assessment, } \\
\text { Erasmus University Rotterdam, } \\
\text { P O Box 1738, } \\
\text { 3000 DR Rotterdam, } \\
\text { The Netherlands }
\end{array}
$$

\section{Athletes and fenoterol}

In a review of doping in athletes by $\mathrm{Dr}$ Dekhuijzen published recently in Thorax ${ }^{1}$ the substance fenoterol was included in table 2 which listed respiratory drugs permitted by the International Olympic Committee (IOC). However, according to the IOC fenoterol is prohibited. Only salbutamol, salmeterol, and terbutaline are permitted by inhaler to prevent or treat asthma or exercise induced asthma. A written notification is necessary.

To prevent positive doping cases caused by misinformation of athletes and their advisors which might cause questions of regress, it is necessary to print a correction.

$$
\begin{array}{r}
\text { M K HENZE } \\
\text { Deutsche Sporthochschule Köln, } \\
50933 \text { Köln, } \\
\text { Germany }
\end{array}
$$

1 Dekhuijzen PNR, Machiels HA, Heunks LMA, et al. Athletes and doping: effects of drugs on
the respiratory system. Thorax 1999;54:1041-6.

AUTHORS' REPLY We thank Dr Henze for this correction. As in the case of formoterol, there is no scientific reasoning given by the IOC for fenoterol not to be permitted by inhalation, in contrast to salbutamol, terbutaline, and salmeterol. There are no specific pharmacological or pharmacodynamic characteristics of inhaled fenoterol or formoterol that would predict a relevant stimulating effect on the respiratory system. For clarity we reproduce here the correct list of permitted respiratory drugs. 
Table 2 Respiratory drugs permitted by the IOC (shortened and adapted from IOC ${ }^{I}$ )

Short acting $\beta_{2}$ adrenoceptor agonists ${ }^{\star}$ Salbutamol Terbutaline

Long acting $\beta_{2}$ adrenoceptor agonists Salmeterol

Anticholinergics

Ipratropium bromide

Methylxanthines

Aminophylline

Choline theophyllinate

Theophylline

Cromones

Sodium cromoglycate

Inhaled corticosteroids ${ }^{\star}$

Beclometasone dipropionate

Budesonide

Fluticasone

Expectorants and cough suppressants

Bromhexine

Dextromethorphan

Codeine

Antihistamines

All known types

* "Permitted by inhaler only to prevent and/or trea asthma and exercise induced asthma. Written notification of asthma and/or exercise induced asthma by a respiratory or team physician is necessary to the relevant medical authority". ${ }^{1}$

${ }^{\star}$ By inhalation and by nasal administration.

P N R DEKHUIJZEN H A MACHIELS

L $M$ A HEUNKS

H F M VAN DER HEIJDEN

R H H VAN BALKOM

Department of Pulmonary Diseases,

Academic Hospital Nijmegen, P O Box 9101

6500 HB Nijmegen,

The Netherlands

1 International Olympic Committee. List of classe of prohibited substances and methods of doping,
1999 .

\section{Asthma education}

Drs Neville and Higgins ask what more can be done to provide better asthma care. ${ }^{1}$ They mention the importance of education but, before we can teach patients, we must resolve our own confusion about treatment.

Evidence shows that it is important to stamp out the inflammatory process in the bronchial tree as soon as the diagnosis of asthma has been confirmed, yet patients are still prescribed a short acting $\beta$ agonist bronchodilator as the drug of first choice. This is given partly as a diagnostic test and partly because step 1 of the BTS guidelines ${ }^{2}$ seems a good place to start. Although the guidelines state that treatment should start at the step most appropriate to the initial severity, little guidance is given as to how this should be assessed.

Bronchodilators have a dramatic short term effect so patients learn that these are the correct treatment for their asthma and rapidly become dependent on them; inhalations are repeated as symptoms recur and they start to take much more than the doctor realises or intended. ${ }^{3}$ It is then difficult to introduce steroids as additional treatment as patients feel these drugs are less effective because of their delayed action. The result is that most asthmatic patients persist in using short acting $\beta$ agonists on their own, or sometimes with an inadequate dose of inhaled steroids, to try to control their symptoms. Mucosal inflammation and bronchial hyperreactivity persist, the frequency of symptoms is not reduced, and optimal lung function is never achieved. These patients do not realise the importance of steroids and, when their symptoms become worse, they increase their bronchodilators but delay taking steroids until it is too late to prevent an acute attack.

Another approach to management is to start all new asthmatic patients at step 2 of the BTS guidelines, using a large dose of steroids as soon as the diagnosis has been confirmed by PFR monitoring. There is then no agonising over whether or not to give steroids or what dose to use. These patients learn that steroids are the correct treatment for their asthma. The large initial dose recommended stamps out the active inflammatory process and achieves symptom control with full reversibility and optimal lung function. The dose is then gradually reduced to the minimum necessary to maintain optimum lung function and freedom from symptoms. Beta agonist bronchodilators are not prescribed initially but kept in reserve for emergencies.

The latter approach is being increasingly adopted by asthma nurses and many thinking doctors but some still misinterpret the BTS guidelines and allow their patients to become addicted to $\beta$ agonists.

Perhaps we need guidance on the use of the guidelines?

GEORGE STRUBE
33 Goffs Park Road,
Crawley,
West Sussex RH11 8AX,

1 Neville RG, Higgins BG. Providing better asthma care: what is there left to do? Thorax 1999;54:813-817

2 British Thoracic Society. The British guidelines on asthma management: 1995 review and position statement. Thorax 1997;52(Suppl 1):S121.

3 Price D, Ryan D, Pearce L, et al. The air study: asthma in real life. Asthma f 1999;4:74-8.

AUTHORS' REPLY Dr Strube's letter addresses an interesting and important question. It is an issue which deserves proper debate, and most Thorax readers will recognise that that is exactly what it has had in the recent pages of the BMF. ${ }^{1}$ Because of this, and because the question has, we would suggest, only the most tenuous link to our article, we will reply only briefly.

Dr Strube makes the case for using inhaled steroids in all asthma with conviction, but his supporting arguments are a mixture of circumstantial evidence and his own perception of the psychology of asthmatic patients. There is simply no direct trial evidence to show benefit from blanket administration of inhaled steroids to all new asthmatics. Good evidence certainly exists in asthma of moderate severity or greater, ${ }^{2}$ but the situation is less straightforward in patients with mild asthma where the case is unproven. Since there are valid reasons, aired elsewhere, ${ }^{1}$ for not using inhaled steroids unless necessary, it is fair to ask for some proof before committing patients to long term therapy in this way.

In addition to the lack of evidence, the approach advocated by Dr Strube assumes a certainty of diagnosis which many would feel to be unrealistic at the mild end of the asthma spectrum. It is easy to write that inhaled steroids should be started "as soon as the diagnosis has been confirmed by PFR monitoring", but this is an insensitive test which is least likely to confirm asthma in those in whom the need for inhaled steroids is most debatable.

A further part of his argument is that the current guidelines on introduction of inhaled steroids are misused. This, as Mike Rudolf pointed out in the published debate with Dr Strube, ${ }^{1}$ is irrelevant to the main question; if the guidelines are being misinterpreted, the remedy is to attack the misinterpretation, not the guideline.

We would point out that we are not attempting to prove Dr Strube wrong. We cannot do so, any more than he can prove that he is right. What is important is that guidelines are based on the best evidence available, and at the moment we lack the information needed to resolve the issue. If and when the evidence is strong enough, the recommendation will appear as $\mathrm{Dr}$ Strube wishes. Until then, this is a question of faith rather than fact.

$$
\begin{array}{r}
\text { B G HIGGINS } \\
\text { R G NEVILLE } \\
\text { Freeman Hospital, } \\
\text { High Heaton, } \\
\text { Newcastle upon Tyne NE7 7DN, }
\end{array}
$$
$U K$

1 Strube G, Rudolf M. Should steroids be the first line treatment for asthma? $B M F 2000 ; 320: 47-9$. 2 Haahtela T, Jarvinen M, Kava T, et al. Comparison of a $\beta_{2}$ agonist, terbutaline, with an inhaled corticosteroid, budesonide, in newly detected asthma. N Engl f Med 1991;325:388-92.

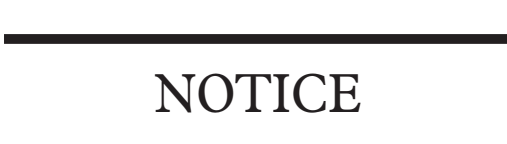

\section{International Pediatric Respiratory and Allergy Congress}

The International Pediatric Respiratory and Allergy Congress will be held on 1-4 April 2001 at the Prague Congress Center, Prague, Czech Republic. For further information contact the Congress Secretariat at the Congress Centre, Czech Medical Society, JEP Sokolská 31, CZ-120 26 Prague, Czech Republic. Telephone +4202 296889 or +4202 297271; fax +4202294610 or +4202 24216836. Email: lonekova@cls.cz 